\title{
Mdig de-represses H19 large intergenic non-coding RNA (lincRNA) by down-regulating H3K9me3 and heterochromatin
}

\author{
Bailing Chen ${ }^{1}$, Miaomiao Yu ${ }^{1}$, Qingshan Chang ${ }^{1}$, Yongju Lu ${ }^{1}$, Chitra Thakur ${ }^{1}$, Danjun $\mathrm{Ma}^{1}$, Zhengping Yi ${ }^{1}$, \\ Fei Chen ${ }^{1}$ \\ 1 Department of Pharmaceutical Sciences, Eugene Applebaum College of Pharmacy, Wayne State University, 259 Mack \\ Avenue, Detroit, MI, USA \\ Correspondence to: Fei Chen, email: fchen@wayne.edu
}

Keywords: mdig, H19, demethylation, prognosis

Received:July 2, $2013 \quad$ Accepted: August 8, $2013 \quad$ Published: August 10, 2013

This is an open-access article distributed under the terms of the Creative Commons Attribution License, which permits unrestricted use, distribution, and reproduction in any medium, provided the original author and source are credited.

\section{ABSTRACT:}

Mineral dust-induced gene (mdig) had been linked to the development of human lung cancers associated with environmental exposure to mineral dust, tobacco smoke or other carcinogens. In the present studies, we demonstrated that the overexpression of mdig in A549 adenocarcinomic human alveolar type II epithelial cells decreases the heterochromatin conformation of the cells and de-represses the transcription of genes in the tandemly repeated DNA regions. Although mdig can only cause a marginal decrease of the total histone $\mathrm{H} 3$ lysine 9 trimethylation (H3K9me3), a significant reduction of $\mathrm{H} 3 \mathrm{~K} 9 \mathrm{me} 3$ in the promoter region of $\mathrm{H19}$, the paternally imprinted but maternally expressed gene transcribing a large intergenic non-coding RNA (lincRNA), was observed in the cells with mdig overexpression. Silencing mdig by either shRNA or siRNA not only increased the level of H3K9me3 in the promoter region of $\mathrm{H} 19$ but also attenuated the transcription of H19 long non-coding RNA. Demethylation assays using immunoprecipitated mdig and histone $\mathrm{H} 3$ peptide substrate suggested that mdig is able to remove the methyl groups from H3K9me3. Clinically, we found that higher levels of mdig and H19 expression correlate with poorer survival of the lung cancer patients. Taken together, our results imply that mdig is involved in the regulation of $\mathrm{H} 3 \mathrm{~K} 9 \mathrm{me} 3$ to influence the heterochromatin structure of the genome and the expression of genes important for cell growth or transformation.

\section{INTRODUCTION}

Mineral dust-induced gene (mdig) was first identified in people with chronic lung diseases resulting from occupational exposure to mineral dust in the mining industry $[1,2]$. This gene was independently identified in human glioblastoma cell line T98G cells that overexpress the c-Myc oncogene and named as myc-induced nuclear antigen 53 (mina53) [3]. In addition, mdig was found to be a constitutive nucleolar component in a number of cell types from Xenopus laevis to humans and was also named nucleolar protein 52 (NO52) [4]. An elevated expression of mdig has been observed in some human cancers, including lung cancer [2], colon cancer [5], esophageal squamous cell carcinoma [6], gingival squamous cell carcinoma [7], lymphoma [8], renal cell carcinoma [9], neuroblastoma[10], gastric cancer[11], hepatocellular carcinoma[12], and cholangiocarcinoma [13]. The mdig protein contains a conserved $\mathrm{JmjC}$ domain that was found in the family of $\mathrm{Fe}$ (II) and 2-oxoglutarate (2OG)dependent dioxygenase enzymes that serve as histone demethylases [14]. Our previous study implicated that mdig is involved in reducing the trimethylation of histone H3 lysine9 (H3K9me3) in the human bronchial epithelial cell line, BEAS-2B [2]. This notion was supported by the fact that the increased expression of mdig is inversely correlated with the level of $\mathrm{H} 3 \mathrm{~K} 9 \mathrm{me} 3$ in the majority of human lung cancer samples examined. In addition, evidence suggests that mdig contributes to cell growth regulation, possibly by promoting cell cycle entrance from G1 phase to S phase and/or the synthesis of rRNA [1-3]. Furthermore, mdig had been shown to be capable of affecting gene expression outside the nucleolus, for example, by repressing IL-4 expression in T helper 
cells [15]. Most recently, mdig has been implicated as a 2-oxoglutarate oxygenase that is responsible for the histidyl hydroxylation of Rpl27a, a subunit of the $60 \mathrm{~S}$ ribosome that is important for protein translation [16].

H19 is a paternally imprinted but maternally expressed oncofetal gene transcribing a large intergenic non-coding RNA (lincRNA) and is located on chromosome 11p15.5 in humans. During the earlier period of embryogenesis, both paternal and maternal $\mathrm{H} 19$ alleles are expressed. In most adult tissues, however, the paternal H19 allele is silenced due to the formation of a high order heterochromatin structure in the H19 gene locus [17, 18] as a result of both DNA methylation and $\mathrm{H} 3 \mathrm{~K} 9 \mathrm{me} 3$ $[19,20]$. The role of H19 in cancer development has been a matter of debate since its discovery in 1990 [2123]. The possible tumor suppressor-like function of H19 was derived from the observed tumor growth inhibition resulting from the H19 cDNA transfection of G401transformed kidney cells and the fact that H19 serves as a precursor of microRNA-675 (miR-675) that targets insulin-like growth factor 1 receptor (IGF1R) [24, 25]. However, several lines of evidence suggest that H19 is more likely an oncogene, rather than a tumor suppressor. First, a number of human cancers, including hepatocellular carcinoma, lung cancer, esophageal cancer, colorectal cancer, bladder cancer, prostate carcinoma, Ewings' sarcoma, and germ cell carcinoma, exhibited increased expression of H19 [22]; secondly, the ectopic expression of H19 enhances the tumorigenicity of breast cancer cells [26]; thirdly, silencing H19 by siRNA attenuated the clonogenicity and anchorage-independent growth of the lung cancer cells and breast cancer cells [27]; lastly, the expression of H19 is up-regulated by both c-Myc and E2F1 oncogenes [23, 27].

We previously reported an increased expression of H19 in hepatocellular carcinoma with higher JNK1 activation $[28,29]$. Because mdig has been implicated in the regulation of rRNA genes, many of which are repressed due to the heterochromatin conformation of the gene loci [30,31], we aimed to explore whether mdig is also capable of regulating the expression of genes in tandemly repeated DNA regions, such as H19, a lincRNA that is not expressed in adult tissues as a result of the highly condensed heterochromatin structure in the promoter and the differentially methylated region (DMR)/ imprint control region (ICR) of the H19 gene. Our data showed that mdig enhances $\mathrm{H} 19$ expression by reducing the level of $\mathrm{H} 3 \mathrm{~K} 9 \mathrm{me} 3$ in the promoter and ICR region of the $\mathrm{H} 19$ gene. The in vitro demethylation assay using immunoprecipitated mdig protein and histone $\mathrm{H} 3$ peptide containing $\mathrm{H} 3 \mathrm{~K} 9 \mathrm{me} 3$ indicated that the mdig is able to demethylate $\mathrm{H} 3 \mathrm{~K} 9 \mathrm{me} 3$. These findings may thus provide a new mechanistic insight into the oncogenic role of the mdig gene in the development of human cancers.

\section{RESULTS}

\section{Mdig reduces nuclear heterochromatin staining by DAPI}

High levels of mdig expression have been found in a number of human cancers. In human lung cancers, our previous data showed an inverse correlation between the levels of mdig protein and H3K9me3 [2]. In the present studies, we initially aimed to determine the contribution of mdig to the growth regulation of the A549 adenocarcinomic human alveolar basal epithelial cells by establishing stably transfected cell lines overexpressing mdig-GFP protein. In a routine examination for the expression of mdig-GFP by fluorescence microscopy, we frequently noted that cells expressing mdig-GFP always showed a dimmed nuclear staining signal by 4',6-diamidino-2-phenylindole (DAPI), a fluorescent dye that binds strongly to repetitive A-T rich DNA (Fig. 1A). In a randomly selected microscopic field, the number of cells that showed mdig-GFP expression but dimmed staining of DAPI was much higher than the cells showing mdigGFP expression and normal or higher DAPI staining (Figs. $1 B$ and $1 C)$. Under high magnification, heterochromatin foci that contain highly condensed and repetitive tandem DNA can be visualized by DAPI staining among the cells without any notable expression of mdig-GFP. These heterochromatin foci, however, were absent in the cells expressing mdig-GFP (Fig. 1D). Because it is known that $\mathrm{H} 3 \mathrm{~K} 9 \mathrm{me} 3$ is enriched in the heterochromatin region [33], we also determined the effect of mdig on $\mathrm{H} 3 \mathrm{~K} 9 \mathrm{me} 3$ in A549 cells by fluorescent microscopy. Indeed, a similar pattern of $\mathrm{H} 3 \mathrm{~K} 9 \mathrm{me} 3$ foci that are roughly overlapping with the heterochromatin foci as stained by DAPI was seen in the cells without mdig-GFP. In contrast, these H3K9me3 foci were faint in the mdig-GFP expressing cells (Fig. 1D, bottom panels).

To exclude the possibility that the above observation was a result of the overexpression of the exogenous protein that might have caused an artificial reduction of the DAPI staining signal, we next evaluated the effect of endogenous mdig on DAPI staining. The level of endogenous mdig was measured by staining the cells with an anti-mdig antibody and a secondary antibody conjugated with Alexa Fluor 680 that emits a red fluorescent signal under fluorescent microscopy. A similar inverse correlation of the levels of endogenous mdig and DAPI staining was observed (Fig. 1E, compare the cells indicated by white arrows to the cells without arrow markers). These data clearly indicate that the expression of mdig reduces the overall level of heterochromatin conformation. 


\section{Marginal effect of mdig on the total H3K9me3 in A549 cells}

The mdig protein contains a conversed JmjC domain, the signature motif of the histone demethylase family of proteins. Although previous studies showed a reduced level of H3K9me3 in the BEAS-2B cells transfected with mdig, direct evidence regarding whether mdig is a histone demethylase is still lacking. In the stably transfected A549 cells that express mdig shRNA that silences mdig, we noted about a 50 to $60 \%$ reduction of mdig protein. However, only a very marginal increase of H3K9me3 and H3K9me1 was observed in these cells (Fig. 2A). No notable effect of mdig on the methylation states of H3K27 was observed (Fig. 2B). To exclude the possibility that the shRNA had a poor silencing effect on mdig in the stably transfected cells, we also used siRNA to silence mdig in A549 cells. Although the siRNA showed much improved efficacy on silencing mdig (Fig. 2C), again, only
A
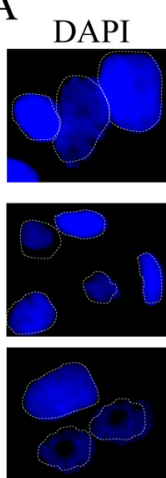

$\mathrm{C}$

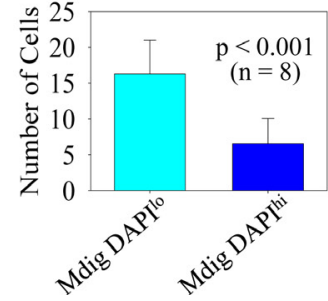

$\mathrm{D}$
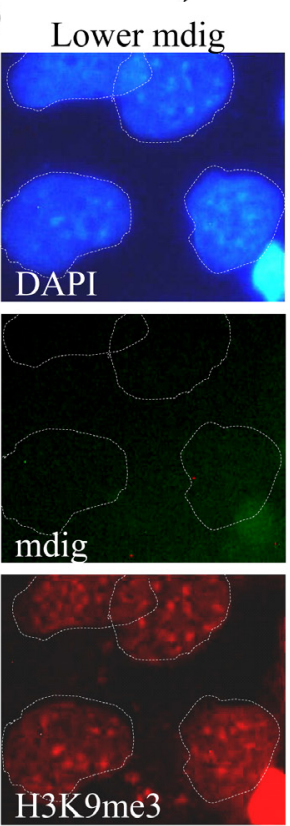

Higher mdig
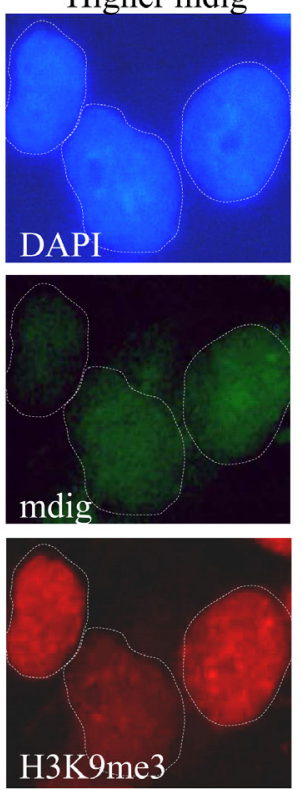

B
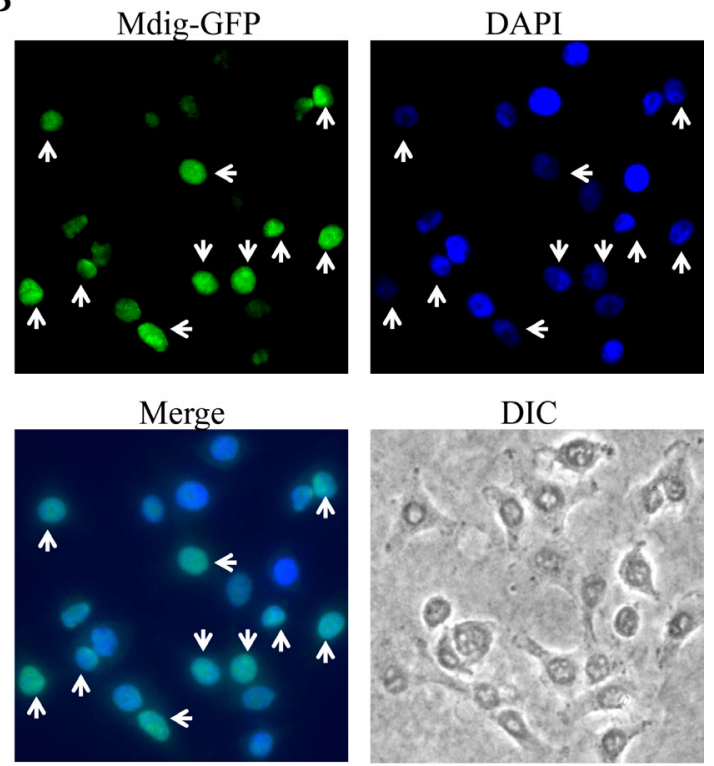

$\mathrm{E}$
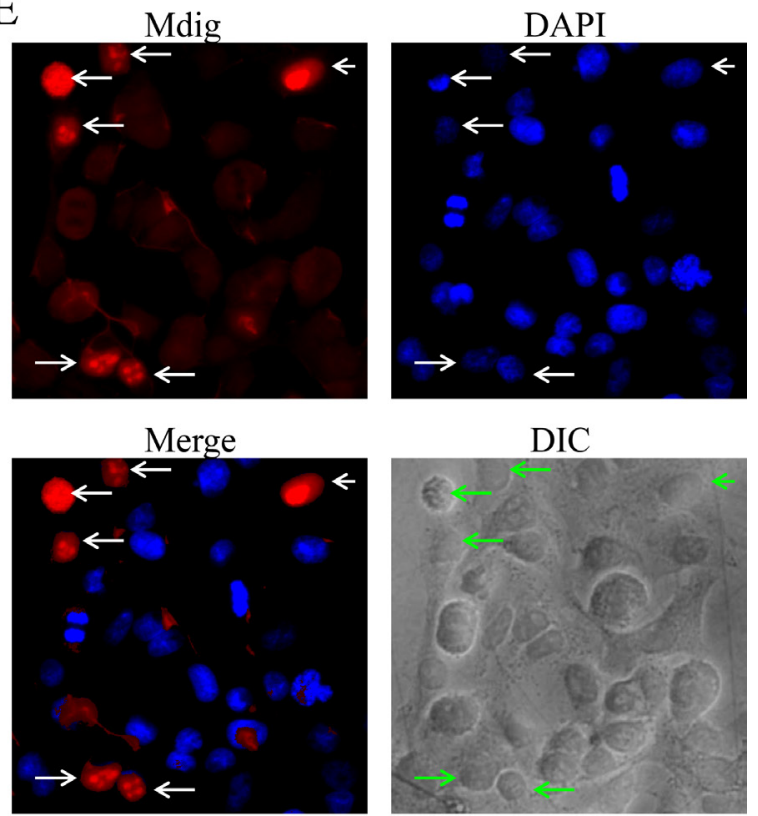

Figure 1: Mdig expression reduces heterochromatin staining. A. Cells expressing mdig-GFP showed reduced DAPI staining; B. A randomly selected field of microscopic image with lower magnification shows the inverse correlation of the GFP signal and the strength of the DAPI signal (arrows); C. Quantification of the cells expressing mdig-GFP with weaker DAPI staining and the cells expressing mdigGFP with normal or strong DAPI staining; D. Mdig expression diminishes the heterochromatin foci as evidenced by the reduced number of bright DAPI-stained foci and H3K9me3 foci. Note the overlapping pattern of the bright DAPI staining foci and the H3K9me3 foci in the cells without mdig-GFP signal; E. Cells expressing a higher level of endogenous mdig showed reduced DAPI staining (arrows). 
a marginal increase of $\mathrm{H} 3 \mathrm{~K} 9 \mathrm{me} 3$ was detected.

To further examine the potential role of mdig on $\mathrm{H} 3 \mathrm{~K} 9 \mathrm{me} 3$, we evaluated the methylation status of histone $\mathrm{H} 3$ protein in several clones of the cells stably expressing mdig. All three mdig stable expression clones showed some degree of reduction in the level of $\mathrm{H} 3 \mathrm{~K} 9 \mathrm{me} 3$ as compared to the clone stably expressing a control vector (Fig. 2D). No conclusive effect of mdig overexpression on H3K27me3, H3K36me3 and H3K4me3 was observed. Consistent with the result of immunoblotting on the effect of mdig shRNA on H3K9me3 (Fig. 2A), immunofluorescent staining also indicated a marginal increase of $\mathrm{H} 3 \mathrm{~K} 9 \mathrm{me} 3$ in the cells stably expressing mdig shRNA (Fig. 2E).

\section{Mdig de-represses the transcription of genes in heterochromatin regions}

Our immunoblotting data showed that mdig only exhibited a very marginal effect on the total $\mathrm{H} 3 \mathrm{~K} 9 \mathrm{me} 3$ level in the cells in which mdig is overexpressed or silenced by siRNA or shRNA (Fig. 2). One possibility of such a weak effect may be a result of the limited activity of mdig on the global level of $\mathrm{H} 3 \mathrm{~K} 9 \mathrm{me} 3$ which is distributed in a wide range of chromatin types, including constitutive heterochromatin, facultative heterochromatin, repressive and non-repressive euchromatin, etc. To determine the potential influence of mdig on a limited scale of epigenetic regulation, we focused on the effect of mdig on the transcription of genes that are known to be silenced in the heterochromatin regions, such as satellite and imprinting loci. H19 and IGF2 are paternally and maternally imprinted genes, respectively, due to the highly repetitive DNA elements between these two gene loci and the developmental formation of a highly condensed heterochromatin structure in their gene loci. Quantitative RT-PCR experiments showed that the transcript levels of H19 and IGF2 were elevated 9.98fold and 1.7-fold, respectively, in the cells that stably overexpressed mdig (Fig. 3A). In addition to H19 and IGF2, we also investigated the level of a long noncoding transcript from the macrosatellite X56 that is packaged in facultative heterochromatin characterized by H3K9me3 and CpG DNA hypermethylation at the active $\mathrm{X}$ chromosome [34]. The overexpression of mdig induces a 2.96-fold increase of macrosatellite X56 transcript levels (Fig. 3A, right panel). Furthermore, 2.8-fold and 3.4-fold increases of c-Myc and Jhdm3a expression were observed in the mdig-overexpressing cells relative to the cells expressing a control vector (Fig. 3B). The increased expression of c-Myc may be important in mediating the growth-promoting feature of the mdig protein, whereas elevated Jhdm3a, a known H3K9me3 demethylase, may
A

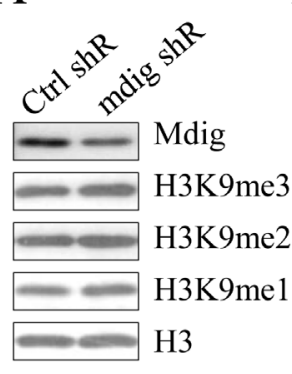

B

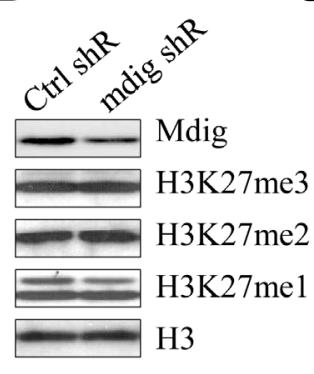

E
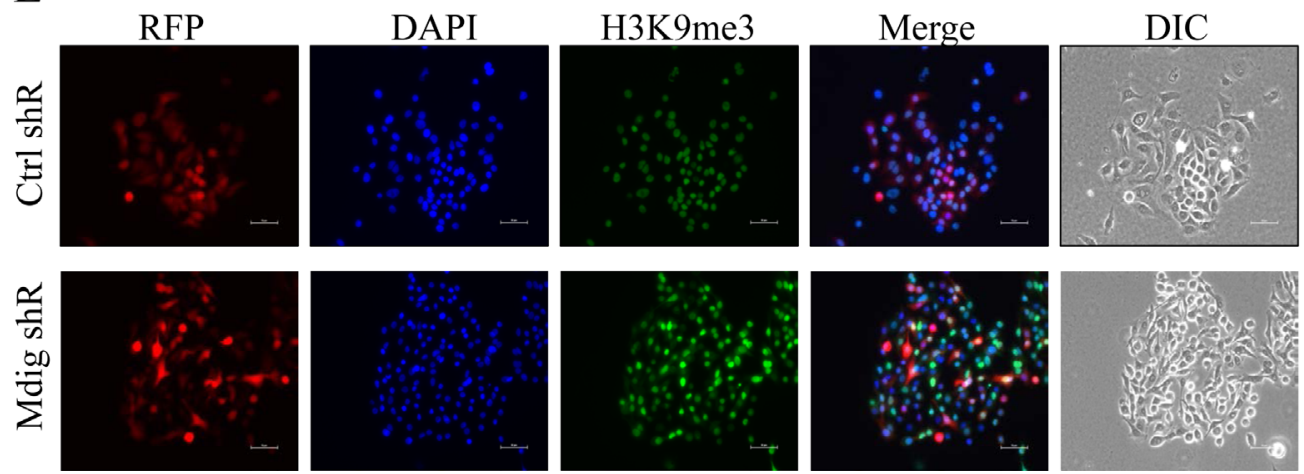

Figure 2: Marginal effect of mdig on total H3K9me3. A \& B. Western blotting detection for the mdig protein and the histone H3 methylation status in the cells stably transfected with control shRNA or mdig shRNA. C. Western blotting detection of the mdig protein and the histone $\mathrm{H} 3$ methylation status in the cells transfected with a control siRNA or mdig siRNA. D. Western blotting detection of the mdig protein and the histone $\mathrm{H} 3$ methylation status in the cells stably expressing a control vector or mdig. E. Immunofluorescent staining of H3K9me3 in the cells stably expressing an RFP-tagged control shRNA or an RFP-tagged mdig shRNA. Nuclei were staining by DAPI. 
contribute to the demethylation of $\mathrm{H} 3 \mathrm{~K} 9 \mathrm{me} 3$ and possibly H3K36me3 in the mdig-expressing cells [35].

Prompted by the highest induction of H19 among the transcripts examined in mdig-overexpressing cells, we next focused our attention on the level of H19 mRNA in the cells in which mdig was silenced by shRNA to validate the role of mdig on the de-repression of genes in the heterochromatin region. We assume that if mdig derepresses $\mathrm{H} 19$ as we observed in the mdig-overexpressing cells, silencing mdig may reduce the transcription of H19. As expected, silencing mdig resulted in a 6.2fold reduction of the $\mathrm{H} 19$ transcript relative to the cells expressing a control shRNA (Fig. 3C).

The H19 gene is located in the short arm and near the end of chromosome 11 in humans. The expression of H19 is regulated by the methylation status of the DNA and histone protein in the promoter and the ICR of the H19 gene [17, 18]. ICR methylation and the formation of $\mathrm{H} 3 \mathrm{~K} 9 \mathrm{me} 3$ on the nucleosomes in this region will prevent the binding of CCCTC-binding factor (CTCF) to the ICR and the intrachromasomal looping of the enhancer to the promoter region of the $\mathrm{H} 19$ gene, leading to the repression of H19 transcription [36]. To test the hypothesis that mdig de-represses $\mathrm{H} 19$ transcription by affecting the level of $\mathrm{H} 3 \mathrm{~K} 9 \mathrm{me} 3$, we determined the abundance of $\mathrm{H} 3 \mathrm{~K} 9 \mathrm{me} 3$ in the promoter and ICR of the H19 gene locus by chromatin immunoprecipitation (ChIP) experiments in mdigoverexpressing cells or cells in which mdig is silenced by
shRNA. Indeed, the overexpression of mdig diminished the enrichment of H3K9me3 in the H19 gene promoter (Fig. 3D). In contrast, silencing mdig with shRNA increased the enrichment of $\mathrm{H} 3 \mathrm{~K} 9 \mathrm{me} 3$ in the promoter and ICR by 12 -fold and 6-fold, respectively, compared to the control shRNA (Fig. 3D, middle and right panels). These data clearly indicate that mdig is capable of de-repressing genes in the heterochromatin region by reducing the level of $\mathrm{H} 3 \mathrm{~K} 9 \mathrm{me} 3$, although mdig has a marginal effect on the global level of $\mathrm{H} 3 \mathrm{~K} 9 \mathrm{me} 3$, as indicated by Western blotting using total cellular proteins (Fig. 2).

\section{Mdig demethylates H3K9me3 on the histone H3 peptide}

As a key regulator and epigenetic marker of heterochromatin, $\mathrm{H} 3 \mathrm{~K} 9 \mathrm{me} 3$ has been extensively studied for its role in the conformation, maintenance and propagation of heterochromatin. The removal of H3K9me3 by histone demethylases decondenses the heterochromatin structure and de-represses the expression of genes in the heterochromatin region featured with tandemly repeated DNA. Uncertainties remain regarding whether mdig possesses histone demethylase activity based on some cellular and biochemical studies [2, 16]. To gain direct evidence showing that mdig may contribute to the demethylation of $\mathrm{H} 3 \mathrm{~K} 9 \mathrm{me} 3$, we
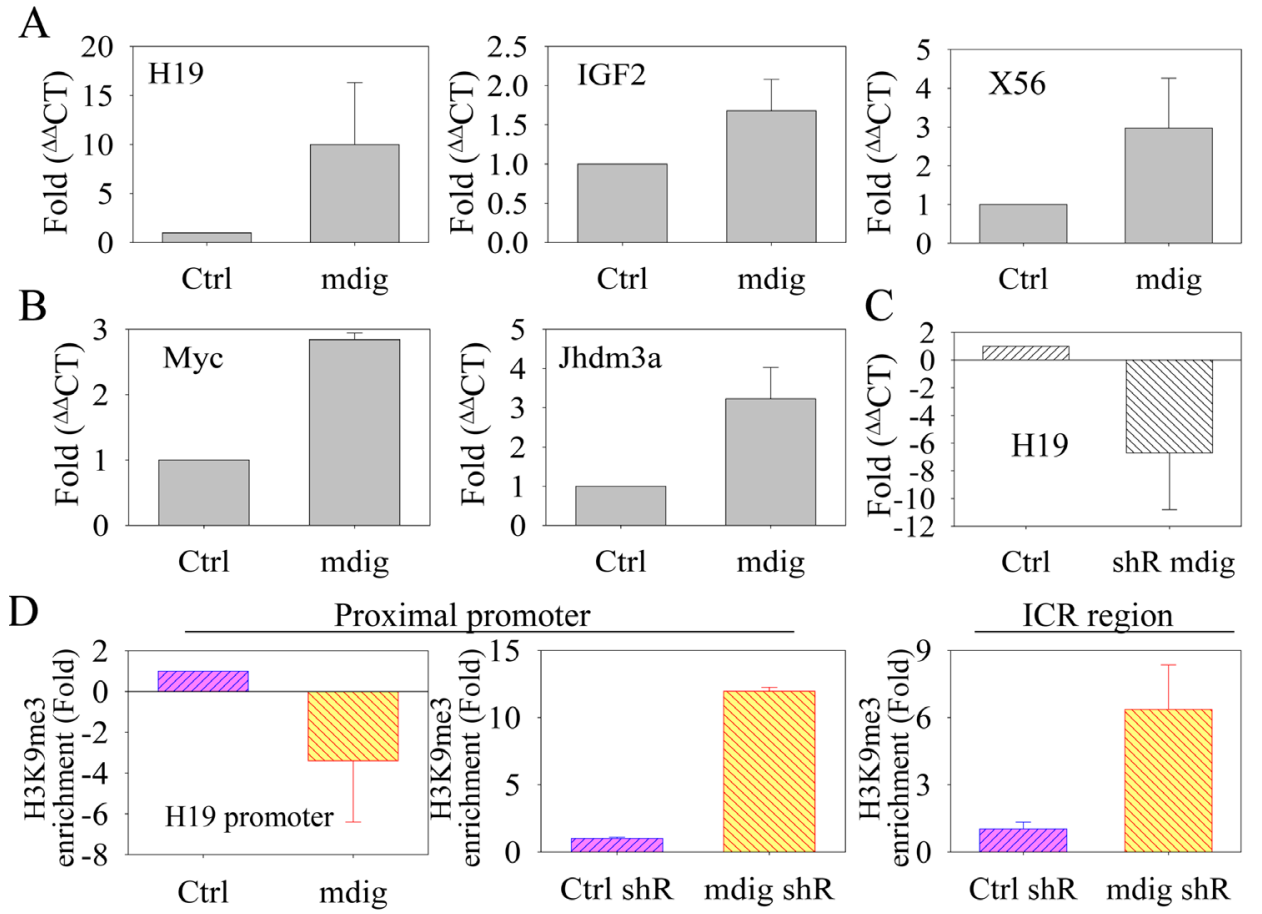

Figure 3: Mdig enhances the expression of genes in the heterochromatin region. A. Quantitative real-time PCR showing that mdig overexpression increases the expression of H19, IGF2 and macrosatellite X56, which are normally repressed by the heterochromatin conformation. B. Quantitative real-time PCR showing that mdig upregulates the expression of c-Myc and Jhdm3a. C. Quantitative real-time PCR showing that silencing mdig by shRNA suppressed the expression of H19. D. Chromatin immunoprecipitation (ChIP) assays showing that mdig overexpression reduces the enrichment of H3K9me3 in the promoter region of the H19 gene (left panel). Silencing mdig by shRNA increased the enrichment of $\mathrm{H} 3 \mathrm{~K} 9 \mathrm{me} 3$ in the promoter (middle panel) and the ICR region (right panel) of the H19 gene. 
incubated immunoprecipitated mdig from the lysates of mdig-overexpressing cells with a histone $\mathrm{H} 3$ peptide containing $\mathrm{H} 3 \mathrm{~K} 9 \mathrm{me} 3$ for 1.5 and $3 \mathrm{~h}$, respectively. Demethylation activity was then determined by tandem mass spectrometry. As shown in Fig. 4, the incubation of the lysine 9 tri-methylated histone $\mathrm{H} 3$ peptide for 1.5 $\mathrm{h}$ resulted in the appearance of $\mathrm{H} 3 \mathrm{~K} 9 \mathrm{me} 2, \mathrm{H} 3 \mathrm{~K} 9 \mathrm{me} 1$, and $\mathrm{H} 3 \mathrm{~K} 9 \mathrm{me} 0$ peptides (Fig. 4A, middle panel, and Fig. 4B). The concentrations of these peptides with different methylation states were increased further when the time of incubation was increased from $1.5 \mathrm{~h}$ to $3 \mathrm{~h}$ (Fig. 4A, bottom panel, and Fig. 4B). The quantification of the demethylation activity of the immunoprecipitated mdig protein toward the histone $\mathrm{H} 3$ peptide substrate suggested that mdig is able to remove one, two and three methyl groups, with the strongest capability to remove two methyl groups from H3K9me3 (Fig. 4B). To exclude the possibility that such a demethylation was a result of contaminated cellular proteins due to non-specific binding in the immunoprecipitation step, we also performed this demethylation reaction using immunoprecipitated c-Jun, a known nuclear protein, or GAPDH, a cytosolic protein. No demethylation activity was detected when the immunoprecipitated c-Jun or GAPDH was included (data not shown).

\section{Increased expression of mdig and $\mathrm{H} 19$ is associated with poorer survival of lung cancer patients}

To investigate whether our findings mentioned above could be relevant to the clinical outcomes of human lung and other cancers, we examined the prognostic value of mdig and H19 in a clinical microarray database of lung cancer [37]. The database collected gene expression data that were obtained by using three different versions of Affymetrix HG-U133 microarrays and the survival information of 1,715 lung cancer patients. Two different mdig probe sets, probes 213188_s_at and 213189_at, are presented in this database. After careful analyses of the sequence information of these two probes, we found that the probe set 213188 _s_at, in fact, detects the far end of the 3'-UTR of mdig mRNA and the antisense of 3'UTR of the $\beta$ - $\gamma$-crystallin domain containing 3 (CRYBG) mRNA. Thus, this probe set was not included in our assay. The probe set 213189 at, nonetheless, detects the open-reading frame (ORF) of mdig mRNA, which may much more accurately detect the true expression level of the mdig mRNA. Accordingly, we used this probe set for the correlation assay of mdig expression with the survival of lung cancer patients. Although the mdig level has no significant correlation with the survival of total lung cancer patients, we noted a strong association

A

B

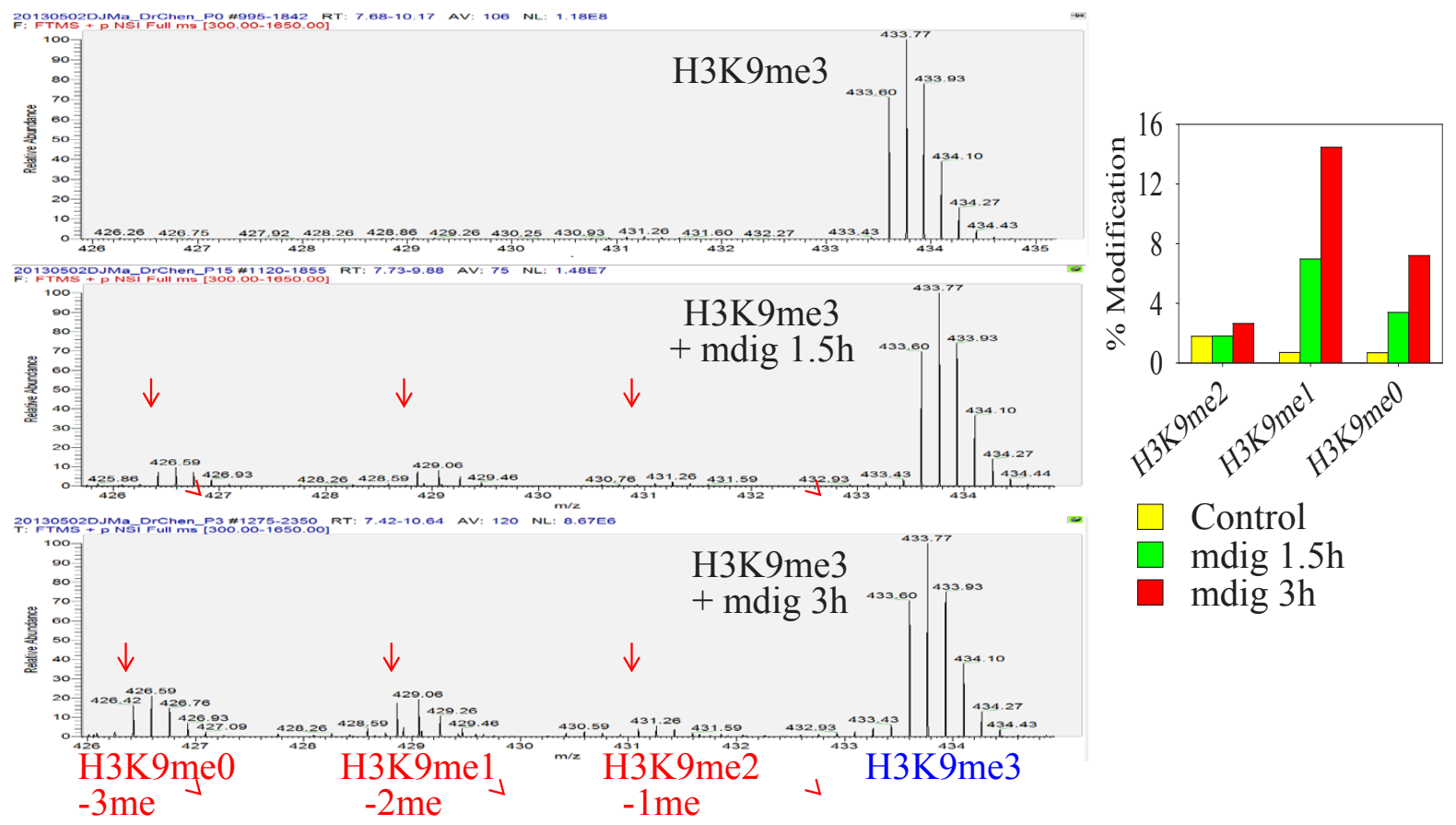

Figure 4: Immunoprecipitated mdig from mdig-GFP expressing cells can demethylate H3K9me3. A. Mass spectrum diagrams showing the mdig-mediated demethylation of $\mathrm{H} 3 \mathrm{~K} 9 \mathrm{me} 3$. Top panel: incubation of H3K9me3-histone H3 peptide with control IgG; middle panel: incubation of $\mathrm{H} 3 \mathrm{~K} 9 \mathrm{me} 3$-histone $\mathrm{H} 3$ peptide with immunoprecipitated mdig protein for $1.5 \mathrm{~h}$; bottom panel: H3K9me3histone $\mathrm{H} 3$ peptide with immunoprecipitated mdig protein for 3.0 h.B. Quantification of the demethylation products. 
between a higher level of mdig with poorer overall survival of the lung cancer patients who were smokers or former smokers (Fig. 5A). Because we noted that mdig enhanced H19 expression by demethylating H3K9me3 in the promoter and ICR region of the H19 gene (Figs. 3 and 4), we next aimed to determine whether higher levels of H19 also predict a poorer prognosis for the lung cancer patients. Indeed, a highly significant inverse correlation of higher H19 expression as determined by probe set 217723 _x_at with the poorer overall survival of total lung cancer patients was observed (Fig. 5B). To determine whether mdig expression can predict patient survival for other types of cancers, we also analyzed mdig expression and patient survival in breast cancer and ovarian cancer. Interestingly, the prognostic power of mdig was also noted for poorer relapse-free survival of the breast cancer patients (Fig. 5C) and poorer progress-free survival of the ovarian cancer patients (Fig. 5D). These results clearly suggested that the level of mdig expression is an important predictive factor for poorer prognoses of lung cancer, breast cancer and ovarian cancer.

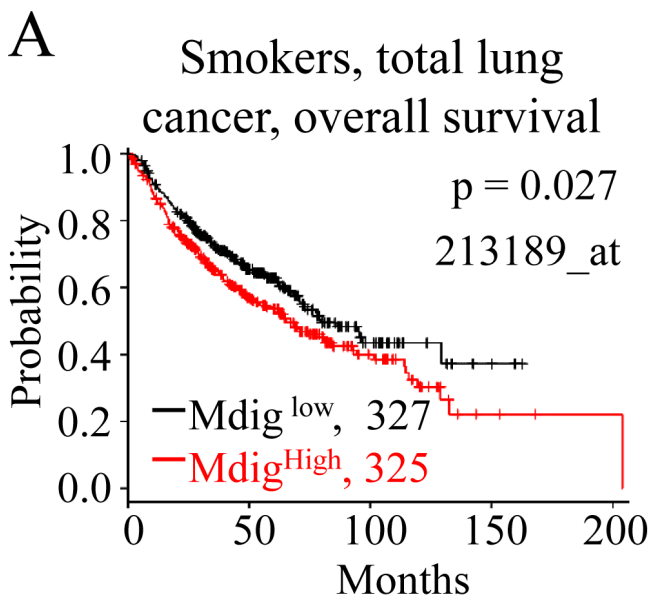

$\mathrm{C}$
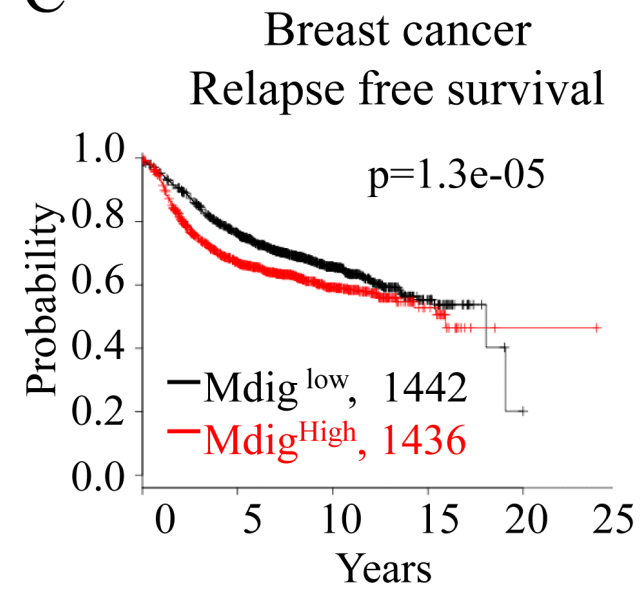

\section{DISCUSSION}

Mdig was first identified as a mineral dust-induced transcript from coal miners' alveolar macrophages by differential display RT-PCR (GenBank BE441202, Jul 25, 2000) [1] and was subsequently found to be a nucleolar protein [4] that might be induced by the c-Myc oncogene [3]. The mdig protein contains a conserved JmjC domain, a signature motif for histone demethylases. However, whether mdig possesses histone demethylase activity remains unclear, despite indirect evidence showing possible contributions of mdig to the demethylation of $\mathrm{H} 3 \mathrm{~K} 9 \mathrm{me} 3$ in the overexpression or siRNA-based silencing experiments in vitro. Because mdig was first identified from patients with occupational lung diseases, whether there is an association between mdig expression and the pathogenesis of human lung cancers remains a compelling question. Our previous reports revealed an elevated level of mdig protein or mRNA in human lung cancers that showed a substantial reduction in the level of H3K9me3 [2], which provided compensatory support to the observations showing decreased levels of H3K9me3

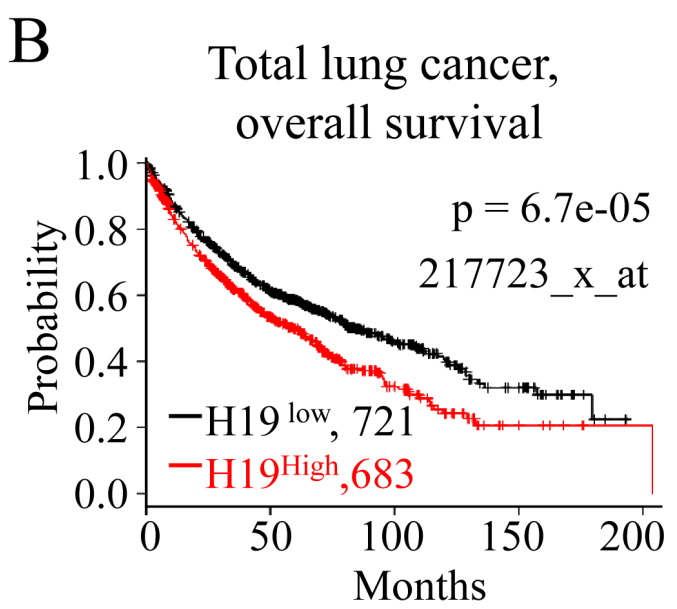

D

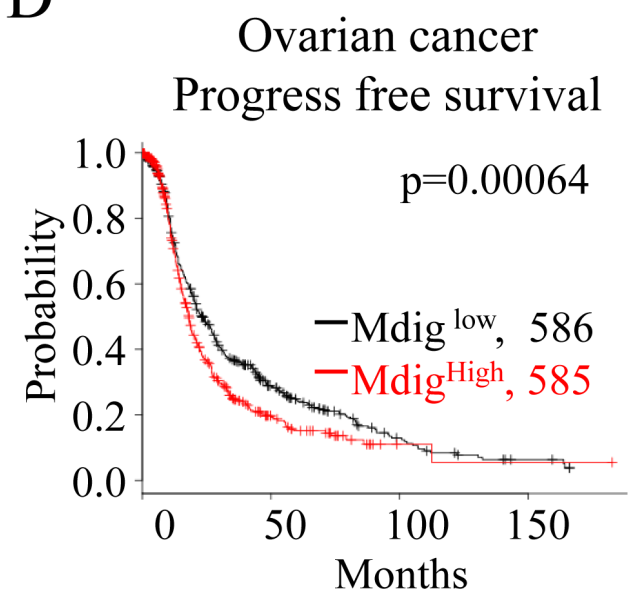

Figure 5: Higher expression of mdig and H19 is associated with poorer survival of cancer patients. A. Kaplan-Meier plot showing poorer survival of the lung cancer patients who were smokers or former smokers and had higher expression of mdig mRNA. B. Higher level of H19 expression correlates with poorer survival of lung cancer patients. C \& D. Higher level of mdig is associated with poorer relapse-free survival of the breast cancer patients and poorer progress-free survival of the ovarian cancer patients. 
in mdig-overexpressing cells.

Recent studies by Ge et al. [16] concluded that recombinant mdig is a protein hydroxylase that catalyzes the histidyl hydroxylation of the ribosomal protein Rp127a without detectable demethylase activity toward histone proteins. A similar observation was made by screening the JmjC family proteins for possible histone demethylases [14]. There are several possible explanations for the failure to detect the demethylase activity of the mdig protein. First, the recombinant mdig protein generated from the engineered bacteria might lack the modifications that are present in mammalian cells. Such modifications, e.g., glycosylation, may be necessary for determining the histone demethylase activity but not the hydroxylase activity. Second, the demethylase activity of mdig may require assistance from other co-factors in addition to the essential components in a test tube demethylation assay. Third, mdig itself may be not a bona fide histone demethylase but may be able to regulate other histone demethylases in terms of their expression or chromatin binding to influence the methylation status of the histone or other proteins.

To circumvent the pitfalls originating from bacterially-expressed recombinant mdig protein, we applied immunoprecipitation-purified mdig protein from the mdig-overexpressing cells to our demethylation assay using histone $\mathrm{H} 3$ peptide. The demethylation reaction was evident due to appearance of the demethylated products following the incubation of mdig protein with the peptide containing $\mathrm{H} 3 \mathrm{~K} 9 \mathrm{me} 3$ (Figs. 4A and 4B). H3K9me3 is a hallmark of heterochromatin that mostly contributes to the transcriptional silencing of genes by recruiting heterochromatin protein 1 (HP1) for heterochromatin propagation and condensation. The decreased staining signal of DAPI that targets heterochromatin in mdigexpressing cells can be interpreted as an additional sign of mdig's role in $\mathrm{H} 3 \mathrm{~K} 9 \mathrm{me} 3$ demethylation. However, it should be noted that the demethylation capability of mdig is relatively weak toward bulk histone $\mathrm{H} 3$, as evidenced in the immunoblotting experiments. Such a weak activity may reflect two general facts: first, mdig is mostly localized in the nucleoli, which contain a very small portion of the H3K9me3-enriched chromatin; second, mdig is one of many demethylases that are overpowered by a number of methytransferases in a given cell or tissue. Nevertheless, mdig is still capable of reducing the level of $\mathrm{H} 3 \mathrm{~K} 9 \mathrm{me} 3$ on some specific genes, such as the gene loci of rRNAs, as we reported previously, and H19, as reported here.H19 and the majority of rRNA genes are silenced in differentiated cells by the heterochromatin conformation resulting from DNA methylation and $\mathrm{H} 3 \mathrm{~K} 9 \mathrm{me} 3$. The demethylation of $\mathrm{H} 3 \mathrm{~K} 9 \mathrm{me} 3$ will relax the heterochromatin and de-repress the expression of $\mathrm{H} 19$ and rRNA that are important for cell growth. Mdig appears to be able to up-regulate the expression of IGF2, macrosatellite X56, c-Myc, and Jhdm3a, which might be achieved through either weakening the heterochromatin structure (IGF2 and macrosatellite X56) or an unexplored, demethylation independent mechanism (c-Myc and Jhdm3a).

$\mathrm{H} 3 \mathrm{~K} 9 \mathrm{me} 3 \mathrm{has}$ a fundamental role in gene silencing, DNA repair, the pluripotency of the stem cells, and cell lineage differentiation through heterochromatin compaction. The misregulation of $\mathrm{H} 3 \mathrm{~K} 9 \mathrm{me} 3$ and heterochromatin conformation have been observed in a number of human cancers [38]. In the mammalian genome, the density of $\mathrm{H} 3 \mathrm{~K} 9 \mathrm{me} 3$ is high in satellite DNAs, rDNA, imprinted loci, and telomeres that contain multiple repetitive DNA sequences. It is widely accepted that reduced levels of $\mathrm{H} 3 \mathrm{~K} 9 \mathrm{me} 3$ are associated with genomic instability [39]. Thus, aberrant expression of mdig may influence the integrity of the genome, leading the cells to be prone to malignant transformation. Furthermore, since there are observations indicating a $\mathrm{H} 3 \mathrm{~K} 9 \mathrm{me} 3$ dependency in the repression of the key stemness genes, most notably the Oct $3 / 4$, Nanog and Sox 2 that are silenced in differentiated cells $[40,41]$, the activation or overexpression of mdig may provide a favorable scenario for reprogramming the somatic cells into stem cells or cancer stem cells.

H19 is a developmentally regulated gene that transcribes a lincRNA. The status of allele-specific imprinting and the expression of H19 are determined largely by $\mathrm{H} 3 \mathrm{~K} 9 \mathrm{me} 3$ and DNA methylation in the ICR and the promoter region of this gene locus. Both H19 lincRNA itself and its derived miR-675 has been linked to oncogenesis [23]. There is evidence showing that $\mathrm{H} 19$ can affect the expression profiles of genes involved in epithelial-to-mesenchymal transition (EMT), angiogenesis, and cancer cell metastasis [23]. Furthermore, $\mathrm{H} 19$, as a precursor of miR-675, may antagonize the tumor suppressor function of retinoblastoma (RB) through miR-675-mediated translational repression, which was reported to be an important mechanism involved in the pathogenesis of human colorectal cancer [42]. Accordingly, the demethylation of $\mathrm{H} 3 \mathrm{~K} 9 \mathrm{me} 3$ by mdig and the subsequent de-condensation of the heterochromatin in the ICR and promoter region of the H19 gene will lead to a looping chromatin conformation favoring H19 transcription, which provides the cells with the advantage of proliferation and malignant transformation.

Taken together, our data highlight that mdig is capable of weakening the heterochromatin conformation by reducing the level of $\mathrm{H} 3 \mathrm{~K} 9 \mathrm{me} 3$, leading to the derepression of the genes in the heterochromatin region. Our findings also indicate that mdig is indeed a protein with $\mathrm{H} 3 \mathrm{~K} 9 \mathrm{me} 3$ demethylase activity, which underscores the novel mechanism of mdig in cancer development. It is important to further unravel how the expression and activity of mdig are regulated during the cellular response to extracellular stimuli, such as mineral dust, tobacco smoke, UV radiation, and other environmental carcinogens. In future studies, it would be interesting 
to explore the feasibility of targeting mdig and other H3K9me3 demethylases as a novel strategy in cancer therapy.

\section{MATERIALS AND METHODS}

\section{Cell culture}

The human lung adenocarcinoma epithelial cell line A549 was purchased from the American Type Culture Collection (ATCC, Manassas, VA). The cells were cultured in RPMI-1640 medium (Invitrogen, Grand Island, NY) supplemented with 5\% fetal bovine serum and $1 \%$ penicillin-streptomycin (Sigma, St. Louis, MO) in a $37^{\circ} \mathrm{C}$ humidified incubator in the presence of $5 \% \mathrm{CO}_{2}$. The cells were dislodged with $0.05 \%$ trypsin (Sigma) when they reached $70-80 \%$ confluence.

\section{Cell transfection}

For the cell transfection experiments with mdig overexpression and shRNA/siRNA silencing, $5 \times 10^{5}$ cells were seeded into each well of 6 -well plates. Cell transfection was performed when the cells reached to 60$70 \%$ confluence using Lipofectamine 2000 (Invitrogen). The mdig-GFP expression vector, control vector, RFPconjugated mdig shRNA, and RFP-conjugated control shRNA were purchased from OriGene (Rockville, MD). Stably transfected clones were established by the addition of puromycin $(2 \mu \mathrm{g} / \mathrm{ml})$ for 2 to 3 weeks. The GFP- or RFP-positive clones were selected under fluorescent microscopy. The overexpression or silencing of mdig was determined by Western blotting. In some experiments, siRNA was used for the transient silencing of mdig. Both the control siRNA and the mdig-specific siRNA were purchased from Qiagen (Valencia, CA). The cells $\left(5 \times 10^{5} /\right.$ well $)$ in 6 -well plates were reverse transfected immediately during the period of cell seeding by $50 \mathrm{nM}$ siRNA per well and forward transfected $24 \mathrm{~h}$ later by 50 nM siRNA per well using the Lipofectamine RNAiMAX reagent (Invitrogen) according to the manufacturer's instructions. After incubating for another $24 \mathrm{~h}$ or $48 \mathrm{~h}$, cell lysates were prepared for RNA or protein extraction.

\section{Western blotting}

Cells were lysed using RIPA buffer (Millipore, Billerica, MA) supplemented with phosphatase/protease inhibitor cocktail and $1 \mathrm{mM}$ PMSF through sonication and centrifugation. The proteins in the supernatants were collected and quantified using a Micro BCA Protein Assay Reagent Kit (Thermo Scientific, Pittsburgh, PA). The proteins were boiled in LDS sample buffer (Invitrogen) containing $1 \mathrm{mM}$ dithiothreitol before loading on 10 or $15 \%$ SDS-PAGE gels. Following electrophoretic separation, the proteins were transferred onto PVDF membranes (Invitrogen) that were then blocked in 5\% non-fat milk/Tris-buffered saline with $0.05 \%$ Tween-20 (TBS-T) at room temperature for $1 \mathrm{~h}$. The membranes were incubated sequentially with primary and the second antibodies, followed by image development using CDPStar Reagent (New England Biolabs, New England, MA) and X-ray film.The primary antibodies applied in the experiments include the antibodies against mdig/ mina53, H3K9me3, H3K9me2, H3K9me1, H3K27me3, H3K27me2, H3K27me1, H3K36me3, H3K36me2, H3K36me1, H3K4me3, H3K4me2, and H3K4me1. All antibodies were purchased from Abcam (Cambridge, MA).

\section{Chromatin immunoprecipitation (ChIP)}

ChIP was performed using a Chromatin Immunoprecipitation Assay Kit (Millipore), following the manufacturer's instruction. Briefly, genomic DNA-protein complexes were immunoprecipitated using anti-H3K9me3 antibody or normal rabbit IgG (Santa Cruz Biotechnology, Santa Cruz, CA) as a control. After sonication, the precipitated DNA was amplified by SYBR Green-based quantitative real-time PCR (Roche, LightCycler 480) using primers encompassing the promoter and ICR regions of the $\mathrm{H} 19$ gene. The ChIP PCR primers are (the numbers in parentheses indicate the sequence regions corresponding to the GenBank ID AF125183):

$$
\begin{aligned}
& \text { 5'-CCAGCCATGTGCAAAGTATG-3' (9747-9766) } \\
& \text { 5'-CCATCCTGGAATTCTCCAAA-3' (9939-9920) } \\
& \text { 5'-GCGGTCTTCAGACAGGAAAG-3' (9468-9487) } \\
& \text { 5'-CACGTTCCTGGAGAGTAGGG-3' (9673-9654) } \\
& \text { 5'-TCTTCAGGTCGGGCATTATC-3' (8112-8131) } \\
& \text { 5'-GCTGTCCTTAGACGGAGTCG-3' (8290-8271) }
\end{aligned}
$$

\section{Real-time PCR}

Total RNAs were extracted from the cells using TRIzol Reagent and subjected to reverse transcription using SYBR Green High-Capacity cDNA Reverse Transcription Kits (Applied Biosystems, Foster City, CA) using a LightCycler 480 instrument. The primers include: H19 5'-AAAGACACCATCGGAACAGC-3' and 5'-AGAGTCGTGGAGGCTTTGAA-3'; IGF2 5'-TCCTCCCTGGACAATCAGAC-3' and 5'-AGAAGCACCAGCATCGACTT-3'; Jhdm3a 5'-CTGTCCATAAAATATCGAAATACCCTA-3' and 5'-TACAGTATATAAATACATAATTTGGGC-3'; c-Myc 5'-TACCCTCTCAACGACAGCAG-3' and 5'-TCTTGACATTCTCCTCGGTG-3'; and macrosatellite X56 5'-CTCAGGTCTCTTGGCTTTGC-3' and 5'-GTGCGGAGGGTAGAGTGGTA-3'. 


\section{Immunofluorescent microscopy}

Cells were seeded in a 24-well plate $\left(6 \times 10^{4}\right)$ in $1 \mathrm{ml}$ medium per well and cultured for $24 \mathrm{~h}$. At the end of culturing, the cells were fixed with $4 \%$ formaldehyde in PBS for $15 \mathrm{~min}$ at room temperature and washed 3 times for 5 min using PBS, followed by the sequential incubation in blocking buffer for $60 \mathrm{~min}$, primary antibody diluted in Antibody Dilution Buffer at $4{ }^{\circ} \mathrm{C}$ overnight, and the fluorochrome-conjugated second antibody diluted by Antibody Dilution Buffer for $1 \mathrm{~h}$ at room temperature in the dark. After rinsing the cells 3 times for 5 min each, 4',6-diamidino-2-phenylindole (DAPI) $(0.1 \mathrm{mg} / \mathrm{ml})$ was added on the top of these cells. The immunofluorescent signal was documented under a fluorescence microscope.

\section{In vitro histone demethylation assay}

The in vitro histone demethylation assay was performed according to a previous report [32]. Briefly, mdig protein was enriched from Mdig over-expression cell lines through immunoprecipitation using an mdigspecific antibody (Abcam, MA). Trimethyl histone H3K9 peptide (Epigentek, NY) was incubated with the precipitated complex in histone demethylation buffer [50 mM Hepes-KOH (pH 7.5), $70 \mu \mathrm{M} \mathrm{Fe}\left(\mathrm{NH}_{4}\right)_{2}\left(\mathrm{SO}_{4}\right)_{2}, 1 \mathrm{mM}$ $\alpha$-ketoglutarate, $2 \mathrm{mM}$ L-ascorbic acid] at $37^{\circ} \mathrm{C}$ for $1-3$ hr. For mass spectrum (MS) analysis, the reaction mixture $(1 \mu \mathrm{l})$ was diluted 20 -fold with $0.1 \%$ TFA and desalted by ZipTip pipette tips (Millipore, MA). The peptide was eluted 3 times with $4 \mu \mathrm{l}$ of $30 \% \mathrm{CH}_{3} \mathrm{CN} / 0.1 \%$ formic acid, and the collected elution was separated with a linear gradient of $5-80 \%$ buffer $\mathrm{B}(80 \% \mathrm{ACN}$ and $0.1 \% \mathrm{FA})$ over $20 \mathrm{~min}$ at a flow rate of $250 \mathrm{~nL} / \mathrm{min}$ on a C18-reversed phase column (75 $\mu \mathrm{m}$ ID, $15 \mathrm{~cm}$ length) packed in-house with ReproSil-Pur C18-AQ $\mu$ m resin (Dr. Maisch $\mathrm{GmbH}$ ) in buffer A $(0.1 \%$ FA). A nanoflow Easy-nLC system (Thermo Scientific) was on-line coupled to the Orbitrap Elite instrument (Thermo Scientific). MS data were acquired using a "Top-20-rCID" data-dependent strategy selecting the fragmentation events based on the precursor abundance in the survey scan (300-1650 Th). Full-scan MS spectra were acquired at a target value of $1 \mathrm{e} 6$ and a resolution of 240,000. The charge state rejection function was enabled; charge states were "unassigned", and single charge states were rejected.

\section{REFERENCES}

1. Zhang Y, Lu Y, Yuan BZ, Castranova V, Shi X, Stauffer $\mathrm{JL}$, et al. The Human mineral dust-induced gene, mdig, is a cell growth regulating gene associated with lung cancer. Oncogene 2005; 24:4873-82.

2. Lu Y, Chang Q, Zhang Y, Beezhold K, Rojanasakul Y, Zhao H, et al. Lung cancer-associated JmjC domain protein mdig suppresses formation of tri-methyl lysine 9 of histone H3. Cell Cycle 2009; 8:2101-9.

3. Tsuneoka M, Koda Y, Soejima M, Teye K, Kimura H. A novel myc target gene, mina53, that is involved in cell proliferation. The Journal of biological chemistry 2002; 277:35450-9.

4. Eilbracht J, Kneissel S, Hofmann A, Schmidt-Zachmann MS. Protein NO52--a constitutive nucleolar component sharing high sequence homologies to protein NO66. European journal of cell biology 2005; 84:279-94.

5. Teye K, Tsuneoka M, Arima N, Koda Y, Nakamura Y, Ueta $\mathrm{Y}$, et al. Increased expression of a Myc target gene Mina53 in human colon cancer. The American journal of pathology 2004; 164:205-16.

6. Tsuneoka M, Fujita H, Arima N, Teye K, Okamura T, Inutsuka $\mathrm{H}$, et al. Mina53 as a potential prognostic factor for esophageal squamous cell carcinoma. Clinical cancer research : an official journal of the American Association for Cancer Research 2004; 10:7347-56.

7. Kuratomi K, Yano H, Tsuneoka M, Sakamoto K, Kusukawa J, Kojiro M. Immunohistochemical expression of Mina53 and Ki67 proteins in human primary gingival squamous cell carcinoma. The Kurume medical journal 2006; 53:71-8.

8. Teye K, Arima N, Nakamura Y, Sakamoto K, Sueoka E, Kimura H, et al. Expression of Myc target gene mina53 in subtypes of human lymphoma. Oncology reports 2007; 18:841-8.

9. Ishizaki H, Yano H, Tsuneoka M, Ogasawara S, Akiba J, Nishida N, et al. Overexpression of the myc target gene Mina53 in advanced renal cell carcinoma. Pathology international 2007; 57:672-80.

10. Fukahori S, Yano H, Tsuneoka M, Tanaka Y, Yagi M, Kuwano M, et al. Immunohistochemical expressions of Cap43 and Mina53 proteins in neuroblastoma. Journal of pediatric surgery 2007; 42:1831-40.

11. Zhang Q, Hu CM, Yuan YS, He CH, Zhao Q, Liu NZ. Expression of Mina53 and its significance in gastric carcinoma. The International journal of biological markers 2008; 23:83-8.

12. Ogasawara S, Komuta M, Nakashima O, Akiba J, Tsuneoka M, Yano H. Accelerated expression of a Myc target gene Mina53 in aggressive hepatocellular carcinoma. Hepatology research : the official journal of the Japan Society of Hepatology 2010; 40:330-6.

13. Tan XP, Zhang Q, Dong WG, Lei XW, Yang ZR. Upregulated expression of Mina53 in cholangiocarcinoma and its clinical significance. Oncology letters 2012; 3:103741.

14. Klose RJ, Kallin EM, Zhang Y. JmjC-domain-containing proteins and histone demethylation. Nature reviews Genetics 2006; 7:715-27.

15. Okamoto M, Van Stry M, Chung L, Koyanagi M, Sun X, Suzuki Y, et al. Mina, an Il4 repressor, controls T helper type 2 bias. Nature immunology 2009; 10:872-9. 
16. Ge W, Wolf A, Feng T, Ho CH, Sekirnik R, Zayer A, et al. Oxygenase-catalyzed ribosome hydroxylation occurs in prokaryotes and humans. Nature chemical biology 2012; 8:960-2.

17. Bartolomei MS, Webber AL, Brunkow ME, Tilghman SM. Epigenetic mechanisms underlying the imprinting of the mouse H19 gene. Genes \& development 1993; 7:1663-73.

18. Srivastava M, Hsieh S, Grinberg A, Williams-Simons L, Huang SP, Pfeifer K. H19 and Igf2 monoallelic expression is regulated in two distinct ways by a shared cis acting regulatory region upstream of $\mathrm{H} 19$. Genes \& development 2000; 14:1186-95.

19. Singh P, Lee DH, Szabo PE. More than insulator: multiple roles of CTCF at the H19-Igf2 imprinted domain. Frontiers in genetics 2012; 3:214.

20. Nativio R, Sparago A, Ito Y, Weksberg R, Riccio A, Murrell A. Disruption of genomic neighbourhood at the imprinted IGF2-H19 locus in Beckwith-Wiedemann syndrome and Silver-Russell syndrome. Human molecular genetics 2011; 20:1363-74.

21. Bartolomei MS, Zemel S, Tilghman SM. Parental imprinting of the mouse H19 gene. Nature 1991; 351:153-5.

22. Looijenga LH, Verkerk AJ, De Groot N, Hochberg AA, Oosterhuis JW. H19 in normal development and neoplasia. Molecular reproduction and development 1997; 46:419-39.

23. Matouk I, Raveh E, Ohana P, Lail RA, Gershtain E, Gilon M, et al. The increasing complexity of the oncofetal h19 gene locus: functional dissection and therapeutic intervention. Int J Mol Sci 2013; 14:4298-316.

24. Hao Y, Crenshaw T, Moulton T, Newcomb E, Tycko B. Tumour-suppressor activity of H19 RNA. Nature 1993; 365:764-7.

25. Keniry A, Oxley D, Monnier P, Kyba M, Dandolo L, Smits $\mathrm{G}$, et al. The H19 lincRNA is a developmental reservoir of miR-675 that suppresses growth and Igf1r. Nat Cell Biol 2012; 14:659-65.

26. Lottin S, Adriaenssens E, Dupressoir T, Berteaux N, Montpellier C, Coll J, et al. Overexpression of an ectopic H19 gene enhances the tumorigenic properties of breast cancer cells. Carcinogenesis 2002; 23:1885-95.

27. Barsyte-Lovejoy D, Lau SK, Boutros PC, Khosravi F, Jurisica I, Andrulis IL, et al. The c-Myc oncogene directly induces the H19 noncoding RNA by allele-specific binding to potentiate tumorigenesis. Cancer Res 2006; 66:5330-7.

28. Chang Q, Chen J, Beezhold KJ, Castranova V, Shi X, Chen F. JNK1 activation predicts the prognostic outcome of the human hepatocellular carcinoma. Mol Cancer 2009; 8:64.

29. Chang Q, Zhang Y, Beezhold KJ, Bhatia D, Zhao H, Chen $\mathrm{J}$, et al. Sustained JNK1 activation is associated with altered histone $\mathrm{H} 3$ methylations in human liver cancer. J Hepatol 2009; 50:323-33.

30. Guetg C, Santoro R. Formation of nuclear heterochromatin: the nucleolar point of view. Epigenetics 2012; 7:811-4.

31. Guetg C, Lienemann P, Sirri V, Grummt I, Hernandez-
Verdun D, Hottiger MO, et al. The NoRC complex mediates the heterochromatin formation and stability of silent rRNA genes and centromeric repeats. EMBO J 2010; 29:2135-46.

32. Yamane K, Toumazou C, Tsukada Y, Erdjument-Bromage $\mathrm{H}$, Tempst $\mathrm{P}$, Wong J, et al. JHDM2A, a JmjC-containing H3K9 demethylase, facilitates transcription activation by androgen receptor. Cell 2006; 125:483-95.

33. Beisel C, Paro R. Silencing chromatin: comparing modes and mechanisms. Nature reviews Genetics 2011; 12:123-35.

34. Horakova AH, Moseley SC, McLaughlin CR, Tremblay DC, Chadwick BP. The macrosatellite DXZ4 mediates CTCF-dependent long-range intrachromosomal interactions on the human inactive $\mathrm{X}$ chromosome. Human molecular genetics 2012; 21:4367-77.

35. Klose RJ, Yamane K, Bae Y, Zhang D, Erdjument-Bromage $\mathrm{H}$, Tempst $\mathrm{P}$, et al. The transcriptional repressor JHDM3A demethylates trimethyl histone H3 lysine 9 and lysine 36 . Nature 2006; 442:312-6.

36. Kurukuti S, Tiwari VK, Tavoosidana G, Pugacheva E, Murrell A, Zhao Z, et al. CTCF binding at the H19 imprinting control region mediates maternally inherited higher-order chromatin conformation to restrict enhancer access to Igf2. Proc Natl Acad Sci U S A 2006; 103:106849.

37. Gyorffy B, Lanczky A, Szallasi Z. Implementing an online tool for genome-wide validation of survival-associated biomarkers in ovarian-cancer using microarray data from 1287 patients. Endocrine-related cancer 2012; 19:197-208.

38. Chi P, Allis CD, Wang GG. Covalent histone modifications-miswritten, misinterpreted and mis-erased in human cancers. Nat Rev Cancer 2010; 10:457-69.

39. Peters AH, O'Carroll D, Scherthan H, Mechtler K, Sauer S, Schofer C, et al. Loss of the Suv39h histone methyltransferases impairs mammalian heterochromatin and genome stability. Cell 2001; 107:323-37.

40. Kappes F, Waldmann T, Mathew V, Yu J, Zhang L, Khodadoust MS, et al. The DEK oncoprotein is a $\mathrm{Su}$ (var) that is essential to heterochromatin integrity. Genes \& development 2011; 25:673-8.

41. Hemberger M, Dean W, Reik W. Epigenetic dynamics of stem cells and cell lineage commitment: digging Waddington's canal. Nat Rev Mol Cell Biol 2009; 10:52637.

42. Tsang WP, Ng EK, Ng SS, Jin H, Yu J, Sung JJ, et al. Oncofetal H19-derived miR-675 regulates tumor suppressor $\mathrm{RB}$ in human colorectal cancer. Carcinogenesis 2010; $31: 350-8$. 